\title{
Fbw7 regulates apoptosis in activated $B$ - cell like diffuse large B-cell lymphoma by targeting Stat 3 for ubiquitylation and degradation
}

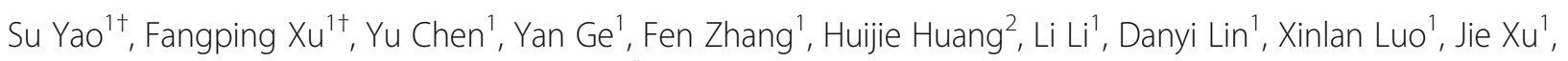
Donglan Luo ${ }^{1}$ Xiaolan Zhu' ${ }^{1}$ and Yanhui Liư ${ }^{1 *}$

\begin{abstract}
Background: The ubiquitin-ligase Fbw7 acts as a tumor suppressor, targeting lots of proto-oncogenes for proteolysis. However, the exact role of Fbw7 in diffuse large B-cell lymphoma (DLBCL) development remains unclear.
\end{abstract}

Methods: We evaluated Fbw7 expression in patient samples of DLBCL using immunohistochemical staining. The effect of Fbw7 overexpression on cell viability and apoptosis was investigated using activated B-cell (ABC) like DLBCL cell lines. The mechanism of Fbw7 activity in DLBCL was investigated using immunoprecipitation, ubiquitination, western blot and qualitative analyses.

Results: The non-germinal center B-cell-like subtype of DLBCL showed reduced Fbw7 expression compared with the germinal center B-cell (GBC) subtype, and low Fbw7 expression was associated with a worse prognosis. Fbw7 overexpression caused decreased cell viability and increased apoptosis rates in the ABC-DLBCL cell lines SU-DHL-2 and OCI-LY-3. Importantly, Stat3 and phospho-Stat3 ${ }^{\text {Tyr705 }}$ stability were reduced following Fbw7 overexpression in ABC-DLBCL cell lines. In HEK293T and SU-DHL-2 cells, we demonstrated that Fbw7 interacts with Stat3 and pStat3 ${ }^{\text {Tyr705 }}$ to regulate their ubiquitylation and degradation. Downstream anti-apoptotic target genes of activated Stat3, including Myc, Survivin, Mcl-1, Pim-1, Bcl-2 and Bcl-xl showed decreased mRNA expression following exogenous Fbw7 overexpression. The negative relationship between Fbw7 and pStat3 ${ }^{\text {Tyr705 }}$ levels was also confirmed in DLBCL patient samples.

Conclusion: The ubiquitin-ligase Fbw7 mediates apoptosis through targeting Stat3 for ubiquitylation and degradation in $A B C-D L B C L$. Thus, our study may offer a promising approach for $A B C-D L B C L$ therapy through Stat3 inhibition.

Keywords: Fbw7, Stat3, DLBCL, Activated B-cell, Apoptosis, Ubiquitylation

\footnotetext{
*Correspondence: yanh_liu@163.com

'Equal contributors

'Department of Pathology, Guangdong General Hospital \& Guangdong

Academy of Medical Sciences, Guangzhou, Guangdong 510080, People's

Republic of China

Full list of author information is available at the end of the article
} 


\section{Background}

Diffuse large B-cell lymphoma (DLBCL) is the most common type of non-Hodgkin lymphoma in adults, contributing to nearly $40 \%$ of new diagnoses [1]. However, DLBCL is involuted both in clinical presentation and morphology. To resolve this problem, DLBCL is now classified as GCB-DLBCL and ABC-DLBCL by genetic profiling $[2,3]$, and patients with the $A B C$ subtype show a significantly poorer outcome compared with the GCB subtype [4]. Immunohistochemistry (IHC) for CD10, Bcl-6 and MUM1 can also differentiate between the GCB and non-GCB subtypes of DLBCL and predicts similar outcomes to genetic profiling [5]. Improved therapies are required for all patients with DLBCL but most urgently for those with the ABC subtype, which is the most chemoresistant and has a worse prognosis [6].

$\mathrm{ABC}$-DLBCL is associated with many different oncogenic events, but all ultimately act on nuclear factor- $\mathrm{k} B$ $(\mathrm{NF}-\mathrm{kB})$ to promote lymphomagenesis [7]. Therefore, signal transducer and activator of transcription 3 (Stat3), which cooperates with NF- $\mathrm{B}$ signaling, is a promising candidate for ABC-DLBCL targeted therapy [8, 9]. Stat3 is constitutively activated in various tumor types, contributing to enhanced proliferation, survival, angiogenesis and immune evasion via several mechanisms [10-14]. Constitutively activated Stat3 in ABC-DLBCL is associated with poor survival [15]; moreover, Stat3 activation is a biomarker for poor survival in DLBCL after rituximab plus cyclophosphamide, doxorubicin, vincristine, and prednisone (R-CHOP) treatment [16].

Fbw7, also known as CDC4, is a substrate recognition element of the evolutionarily conserved SCF-type ubiquitin ligase complex. Acting as a tumor suppressor in human cancer, Fbw7 substrates include several protooncogenes, which are ubiquitylated and tagged for proteasomal degradation [17-26]. Fbw7 genetic deletion results in developmental defects, embryonic lethality and genetic instability, and Fbw7 inactivation by loss of expression or mutation is associated with tumor development [27]. In the hematopoietic system, Fbw7 inactivation leads to hematopoietic stem cell (HSC) depletion by active cell cycling, which can initiate leukemia [28, 29]. Another study showed that HSC differentiation was mediated by Fbw7 regulating Myc stability [30]. Although Fbw7 targets various substrates for degradation that have crucial roles in cell cycle, apoptosis and differentiation, the role of Fbw7-mediated degradation of such targets remains unclear.

Here, we investigate Fbw7 expression in DLBCL. Interestingly, Fbw7 showed lower expression in the nonGCB-DLBCL subtype compared with GCB-DLBCL. The major phenotype associated with Fbw7 overexpression in $\mathrm{ABC}-\mathrm{DLBCL}$ cell lines was the regulation of cell apoptosis. Furthermore, we confirmed that Fbw7 targets
Stat3 and pStat $3^{\text {Tyr705 }}$ for ubiquitin-dependent degradation., and the downstream anti-apoptosis target genes of activated Stat3, including Pim1, Survivin, Mcl-1, Myc, Bcl2 and Bcl-xl showed reduced mRNA expression following exogenous Fbw7 overexpression, in a cell-dependent manner. Together, these results reveal an Fbw7-dependent mechanism that regulates Stat3 ubiquitylation and degradation, providing new insight into the tumor suppressor role of Fbw7, and suggesting that Fbw7 may offer a promising new approach to ABC-DLBCL therapy.

\section{Methods \\ Reagents}

The following antibodies were used in the study: antiFbw7 (for IHC) (H00055294-M02, Abnova, Taipei City, Taiwan), anti-Fbw7 (for western blots) (ab109617, Abcam, Cambridge, UK), anti-Stat3, 12640; antiphospho-Stat3 $^{\text {Tyr705 }}$, 4113; anti-Ubiquitin, 3936 (Cell Signaling Technology, Beverly, MA, USA), anti-Myc tag, 16286-1-AP; anti-Flag tag, 66008-2-Ig; and anti- $\beta$ actin, 60008-2-Ig; anti-Myc, 10828-1-AP; anti-Notch, 10062-2-AP; anti-Jun, 10024-2-AP; anti-DEK, 164481-AP; anti-Mcl1, 16225-1-AP(Proteintech, Rosemont, IL, USA). All other chemicals were purchased from Sigma-Aldrich (St. Louis, MO, USA) and Amresco (Dallas, TX, USA).

\section{Cell culture}

The DLBCL cell lines SU-DHL-2 and OCI-LY-3 were cultured in RPMI-1640 supplemented with 10\% fetal bovine serum (FBS; Gibco, Carlsbad, CA, USA), and HEK293T cells were cultured in DMEM supplemented with $10 \%$ FBS. Cells were maintained in a humidified chamber with $5 \% \mathrm{CO}_{2}$ at $37{ }^{\circ} \mathrm{C}$. The identity of cell lines was confirmed by short tandem repeats-polymerase chain reaction (STR-PCR) genotyping.

\section{Cell transfection}

Vectors containing Fbw7, Stat3 and Ubiquitin were generated by cloning PCR amplified full-length human cDNAs into pcDNA3.1. And the human Stat3 siRNA target sequence was 5'-CACAT GCCAC TTTGG TGTTT CATAA-3'. Lipofectamine 3000 (Invitrogen, Carlsbad, CA, USA) was using to perform transfections according to the manufacturer's instructions.

\section{Tissue samples and IHC}

From 2005 to 2011, 165 human DLBCL samples were collected at the Guangdong General Hospital. The study was approved by Guangdong general hospital Biomedical Research Ethics Committee, and written informed consent was obtained from all the patients. Patients with DLBCL have been followed up for at least 5 years with 
a intervals of 1-3 months until July 2016. The clinicopathological characteristics of the DLBCL patients are showed in Additional files 1 and 2.

Samples were probed using the indicated antibodies. Paraffin-embedded samples were made into a tissue microarray. Staining was evaluated by two blinded individuals, and the scoring criteria was: 0 (no staining), 1 (weak staining), 2 (intermediate staining) and 3 (strong staining). Two pathologist gave a score and the final score was the average.

\section{Apoptosis analysis}

Cells were first transfected with an Fbw7 expression plasmid or vector control, and then Doxorubicin (MP Biomedicals, Illkirch-Graffenstaden France) was used to induce apoptosis. We used the Annexin V-FITC Apoptosis Detection Kit (KeyGEN BioTECH, Nanjing, China), according to the manufacturer's instructions, and the percentage of apoptotic cells was detected by flow cytometry analysis.

\section{Cell viability assay}

For cell viability assay, $5 \times 10^{4}$ cells per well were plated in 96-well, and then incubated with the appropriate medium containing Doxorubicin for $24 \mathrm{~h}$. Assays were performed using the Cell Titer-Glo Luminescent Cell Viability Assay kit (Promega, Madison, WI, USA), according to the manufacturer's instructions.

\section{Western blotting}

Cells were lysed in RIPA lysis buffer (0.1\% SDS, $50 \mathrm{mM}$ Tris containing $150 \mathrm{mM} \mathrm{NaCl}, 1 \%$ Triton X-100 and 1\% sodium deoxycholate; $\mathrm{pH}$ 7.2) with cocktails inhibitor of protease and phosphatase (Merck, Kenilworth, NJ, USA) on ice for $30 \mathrm{~min}$ and centrifuged at $14000 \times g$ for $30 \mathrm{~min}$. According to the protein concentration of $\mathrm{BCA}$ Assay (Pierce, Rockford, IL, USA), $40 \mu \mathrm{g}$ of protein was loaded on $8 \%$ SDS-PAGE gels. And then protein was transferred to PVDF membranes (Millipore, Billerica, MA, USA). Following transfer, blots were blocked, incubated with primary and secondary antibodies and exposed to film using standard procedures.

\section{Immunoprecipitation and ubiquitination assay}

Cells were lysed in RIPA lysis buffer, and the lysates were immunoprecipitated with the indicated antibodies on protein A/G beads (Millipore) overnight. The beads were then washed and boiled in SDS loading buffer. Immunoprecipitated protein complexes were assessed using Western blotting. To detect ubiquitination of Stat3 and pStat3 $3^{\mathrm{Tyr} 705}, 10 \mathrm{mM}$ N-ethylmaleimide was added in the lysis buffer.

\section{RNA extraction and qPCR analysis}

Total RNAs were purified using RNAiso Plus, and firststrand cDNA was generated with PrimeScript RT Master Mix (Takara, Shiga, Japan). qPCR was carried out using SYBR Premix Ex Taq (Takara) on an ABI 7500 PCR system (Applied Biosystems, Carlsbad, CA, USA). The PCR protocol was made up of 40 cycles of clocking at $95{ }^{\circ} \mathrm{C}$ for $5 \mathrm{~s}$ and $60{ }^{\circ} \mathrm{C}$ for $30 \mathrm{~s}$. The data was represented relative to $\beta$-actin, calculated using the $2^{-\Delta \Delta C T}$ method. The primers for PCR reactions are listed in Additional file 3.

\section{Statistical analysis}

Statistical analyses were carried out using the SPSS 16.0 statistical software (SPSS Inc., Chicago, IL, USA). Data are shown as mean $\pm \mathrm{SD}$. The relationships between Fbw7 expression and other clinicopathological factors were determined using Pearson $\chi^{2}$ test. Kaplan-Meier survival analysis was applied to illustrate the outcome relevance of Fbw7 in univariate analysis. Each assay was performed in three repeated experiments. The Student $t$ test was used to compare two groups of independent samples. Correlations between Fbw7 and pStat3 ${ }^{\text {Tyr705 }}$ levels were confirmed using the Spearman rank correlation. Values of $P<0.05$ were considered significant.

\section{Results \\ Decreased Fbw7 expression in non-GCB DLBCL compared with GCB-DLBCL is significantly correlated with poor survival}

To investigate the role of Fbw7 in DLBCL, Fbw7 expression was first analyzed in DLBCL through IHC. Using the Hans program [5], 165 patients were divided into two groups (non-GCB and GCB) based on CD10, Bcl-6 and MUM1 expression by IHC during the clinical diagnosis of pathology; representative IHC images of GCB and non-GCB are shown (Fig. 1a). IHC showed that Fbw7 expression was decreased in the non-GCB group compared with the GCB group $(P<0.01$; Fig. $1 b)$. Low Fbw7 expression and high expression cases were shown (Fig. 1c). The correlation between Fbw7 expression and other clinicopathological features, such as patient sex, age, EB virus status and tumor stage showed no significant differences $(P>0.05$; Additional file 1$)$. KaplanMeier analysis indicated that patients with low Fbw7 expression showed a significantly worse outcome compared with those with high Fbw7 expression (Fig. 1d). The median survival time of DLBCL patients with low Fbw7 expression was 44 months, which was significantly shorter than those with high Fbw7 expression (81 months). Together, these results clearly show that Fbw7 expression is decreased in non-GCB-DLBCL compared with GCB-DLBCL, and low Fbw7 expression is associated with a worse prognosis. 

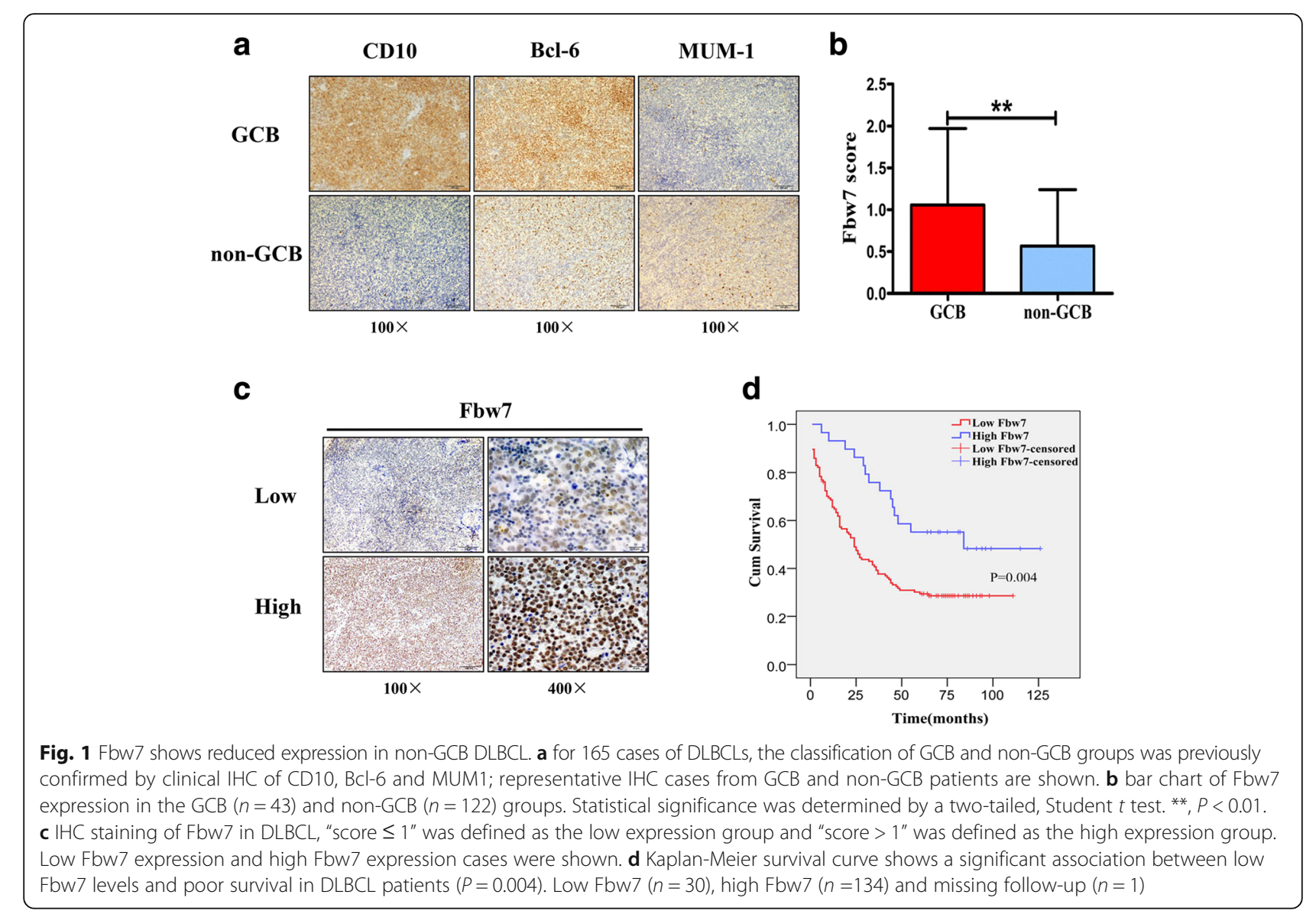

Fbw7 regulates apoptosis in ABC-DLBCL

Based on the Hans algorithm, IHC can be used to differentiate the GCB and non-GCB subtypes of DLBCL, and this predicts survival similar to genetic profiling (GCB and $\mathrm{ABC}$ subtypes). The prevalence of Fbw7 downregulation in non-GCB subtype raises an intriguing possibility that Fbw7 overexpression may be a tumor-inhibiting event in ABC-DLBCL. To test this possibility, the ABC-DLBCL cell lines SU-DHL-2 and OCI-LY-3 were transfected with an Fbw7 expression plasmid, and western blotting confirmed that Fbw7 expression was greatly increased after transfection (Fig. 2a). Next, we investigated how Fbw7 affects the apoptotic response using Doxorubicin to induce apoptosis. To detect the percentage of apoptotic cells, we stained with Annexin-V-PE followed by flow cytometry analysis. As predicted, SU-DHL-2 and OCI-LY-3 cell lines were more sensitive to apoptotic stimuli after transfecting an Fbw7 plasmid compared with vector (Fig. 2b). To investigate the tumor inhibitory effect of Fbw7 in $\mathrm{ABC}$ DLBCL, cells were transfected with the Fbw7 plasmid or vector and treated with Doxorubicin at different concentrations. As expected, cell viability decreased significantly in the Fbw7 overexpression group compared with the vector group (Fig. 2c). Although it's reported that Fbw7 also regulates proliferation by suppressing tumorigenesis in many cancers, our results of CCK8 assays and cell cycle showed no significant difference after Fbw7 overexpression in ABC-DLBCL cell lines (Additional file 4).

\section{Fbw7 regulates the stability of Stat3}

Previous studies have shown that Stat3 is constitutive activated in $A B C-D L B C L$, causing us to evaluate whether Fbw7 regulates Stat3 expression or activity. SU-DHL-2 and OCI-LY-3 cells were transfected with Fbw7 and Stat3 plasmids, and western blotting indicated that Fbw7 decreased the exogenous Stat3 protein level (Fig. 3a). Similarly, Fbw7 overexpression markedly decreased endogenous Stat3 and pStat3 $3^{\text {Tyr705 }}$ levels in a dosedependent manner (Fig. 3b). To investigate whether and how Fbw7 regulates Stat3 stability, SU-DHL-2 cells were treated with an inhibitor of protein synthesis cycloheximide (CHX), and the stability of endogenous Stat 3 and pStat ${ }^{\text {Tyr705 }}$ was examined. The half-life of pStat3 ${ }^{\text {Tyr705 }}$ decreased from $9 \mathrm{~h}$ to approximately $5 \mathrm{~h}$ upon Fbw7 overexpression (Fig. 3c). Similarly, Fbw7 overexpression in OCI-LY-3 cells significantly reduced pStat $3^{\text {Tyr705 }}$ levels (Fig. 3d). These results reveal that Fbw7 reduced Stat3 signaling by promoting its degradation. 


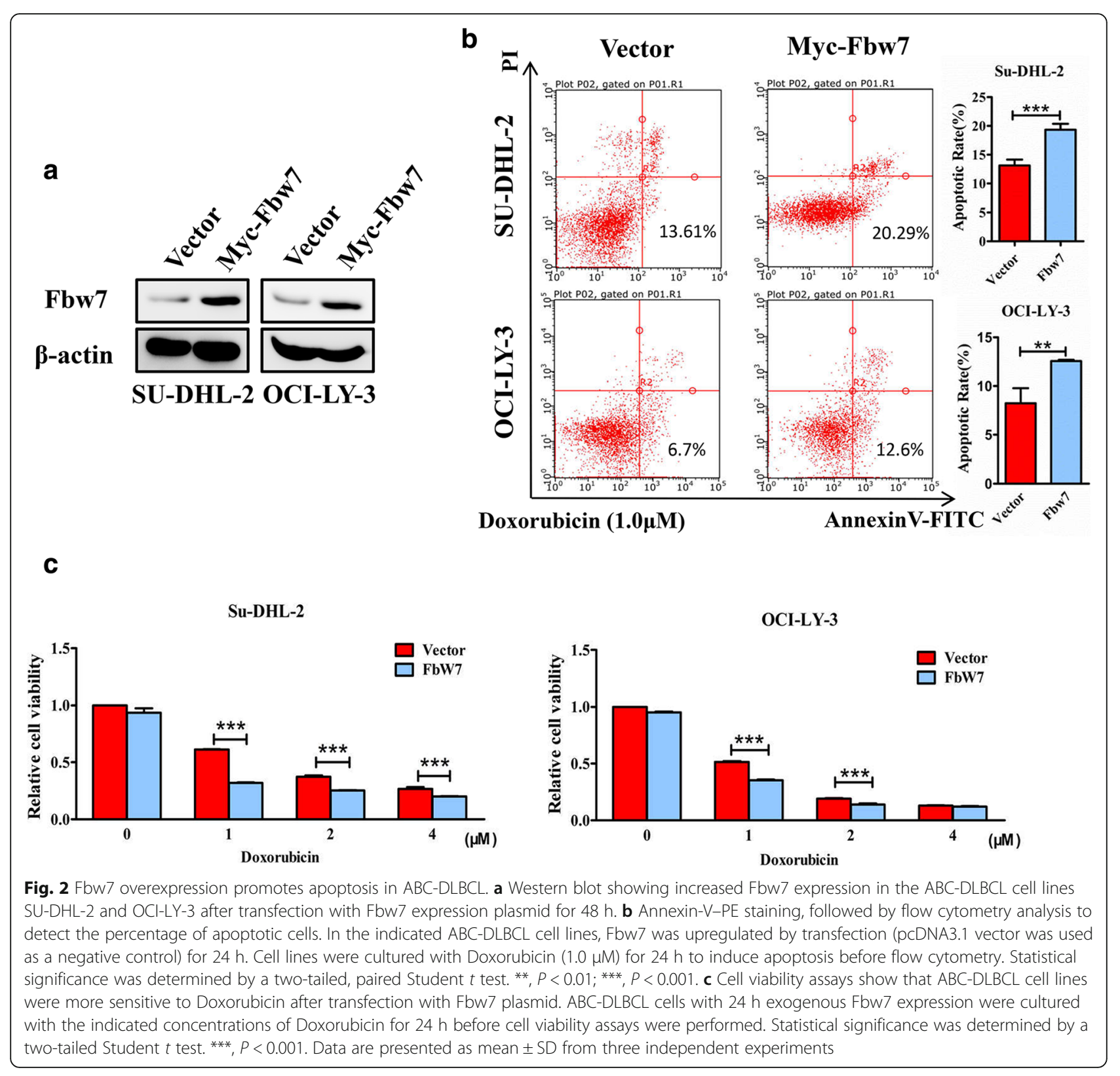

\section{Fbw7 targets Stat3 for ubiquitylation}

Next, we investigated the ability of Fbw7 to interact with Stat3. Myc-Fbw7 and Flag-Stat3 were co-expressed in HEK293T cells. Co-immunoprecipitation analysis showed that Stat3 co-immunoprecipitated with Myc-Fbw7 by anti-Myc antibody (Fig. 4a, top). Similarly, immunoprecipitation of Flag-Stat3 by anti-Flag antibody led to coimmunoprecipitation of Myc-Fbw7 (Fig. 4a, bottom). Endogenous Fbw7 and Stat3 were immunoprecipitated from SU-DHL-2 cells and the presence of endogenous Stat3 and Fbw7 was detected, respectively (Fig. 4b). Similarly, endogenous Fbw7 and pStat $3^{\text {Tyr705 }}$ were immunoprecipitated from SU-DHL-2 cells, and the presence of endogenous pStat $3^{\text {Tyr705 }}$ and Fbw7 was detected, respectively (Fig. 4c). Similar results were obtained in HEK293T cells (Additional file 5). Together, these results show that Fbw7 can interact with Stat3 and pStat $3^{\text {Tyr705. }}$.

Fbw7 is a ubiquitin-ligase that targets several proteins for ubiquitination and degradation. Therefore, we then speculated that Fbw7 might directly regulate Stat3 stability through this activity. To assess this possibility, Flag-Stat3 and HA-ubiquitin were co-expressed with and without Myc-Fbw7 in HEK293T cells. Immunoblotting showed that ubiquitination of Stat-3, and especially pStat $3^{\text {Tyr705, }}$ strongly increased after Fbw7 expression in the presence or absence of MG132, an inhibitor of the 26S proteasome (Fig. 4d and e). Immunoblotting showed similar results for 
a

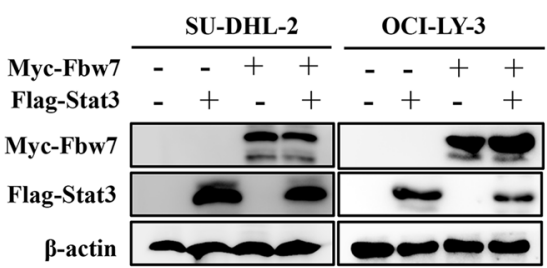

C
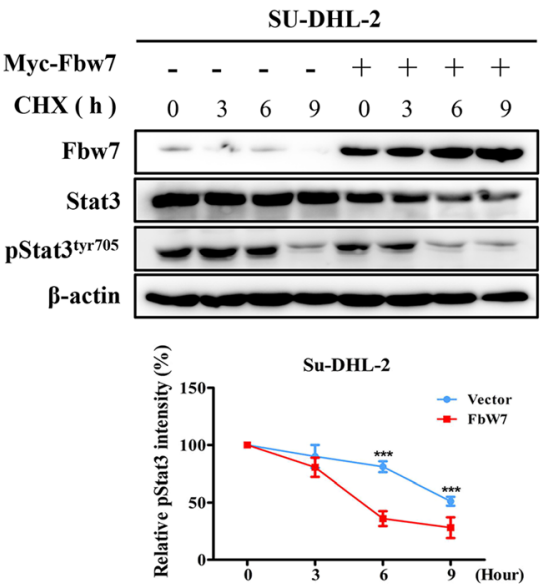

b

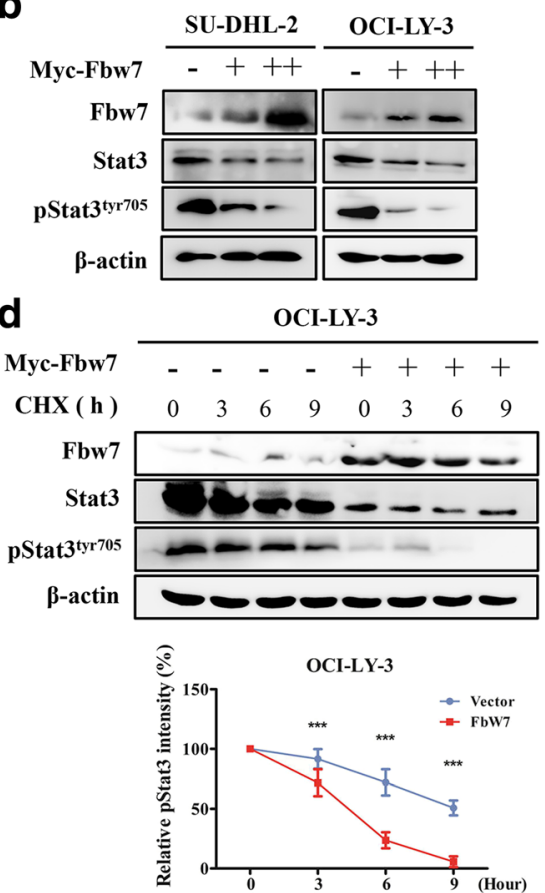

Fig. 3 Fbw7 reduces the stability of Stat3. a western blotting of exogenous Stat3 in SUDHL-2 and OCI-LY-3 cells co-expressing Fbw7. b Fbw7 upregulation decreases endogenous Stat3 and especially pStat3 ${ }^{\text {Tyr705 }}$ expression. $\mathbf{c}$ and $\mathbf{d}$, Fbw7 decreases the stability of Stat3 and pStat $3^{\text {Tyr705 }}$. Myc-Fbw7 was transfected into SUDHL-2 and OCI-LY-3 cells. After treating cells with cycloheximide (CHX; $10 \mathrm{mg} / \mathrm{ml})$ for the indicated time intervals, Fbw7, Stat3 and pStat3 ${ }^{T y}{ }^{\text {Y } 05}$ levels were examined by immunoblotting (top). Western blots were quantified via densitometry, and the mean ratios of the indicated proteins from three independent experiments are shown at the bottom of the figure. Data are shown as mean \pm SD in the line graph for three independent experiments. Statistical significance was determined by a two-tailed unpaired Student $t$ test. ${ }^{* *}, P<0.001$

pStat $3^{\text {Tyr705 }}$ ubiquitination after cells were treated with IL6 cytokines (Fig. 4e). These results conclusively indicate that Fbw7 regulates Stat3 protein levels through ubiquitination and proteasomal degradation.

\section{Fbw7 inhibits apoptosis regulators downstream of Stat3} Constitutively active Stat3 signaling leads to the upregulation of many downstream target genes in ABC-DLBCL, and our data indicate that Fbw7 could inhibit the expression of these genes through degradation of activated Stat3. To test this hypothesis, SU-DHL-2 and OCI-LY-3 cells were transduced with Fbw7 plasmid, and by qPCR showed upregulation of Fbw7 mRNA at the indicated time points (Fig. 5a). No significant change in Stat3 mRNA levels were detected (Fig. 5b), demonstrating that Fbw7 did not affect Stat3 mRNA. However, qPCR revealed that Fbw7 overexpression resulted in a downregulation of several Stat3 target genes that regulate apoptosis, in a cell-dependent manner (Fig. 5c). Results showed a significant reduction in Survivin, Pim-1 and Bcl-2 mRNA levels in SU-DHL-2 cells (right), as well as a significant reduction in Myc, Survivin, Mcl-1, Bcl-2 and Bcl-xl mRNA levels in OCI-LY-3 cells (left). Thus, our results suggest that Fbw7 promotes apoptosis by downregulating these anti-apoptotic genes in $\mathrm{ABC}$-DLBCL.
To demonstrate whether Fbw7 promotes apoptosis through regulating Stat3, siRNA of Stat3, plasmids of Fbw7 and Stat3 was transfected as instructed in ABCDLBCL cell lines, using Doxorubicin to induce apoptosis and staining with Annexin-V-PE followed by flow cytometry analysis. As predicted, SU-DHL-2 and OCI-LY-3 cell lines were more sensitive to apoptotic stimuli after transfecting siRNA of Stat3 or Fbw7 plasmid compared with control groups, and co-expression of Stat3 and Fbw7 plasmids reversed apoptosis compared with Fbw7 groups.

\section{Fbw7 expression is negatively correlated with pStat3 $3^{\text {Tyr705 }}$ levels in DLBCL patient samples}

To further evaluate the relationship between Fbw7 and Stat3, the expression of Fbw7 and Stat3 was analyzed in 56 cases of DLBCL. IHC staining showed that high Fbw7 expression was associated with low pStat3 ${ }^{\text {Tyr705 }}$ expression in Case 1. Inversely, low Fbw7 expression was associated with high pStat $3^{\mathrm{Tyr} 705}$ levels in Case 2 (Fig. 6a). Spearman rank correlation analysis further confirmed that Fbw7 expression was negatively associated with pStat $3^{\mathrm{Tyr} 705}$ expression (Fig. 6b). These results demonstrated that high Fbw7 expression was associated with reduced levels of active Stat3 in human tumor samples, supporting our in vitro data. 

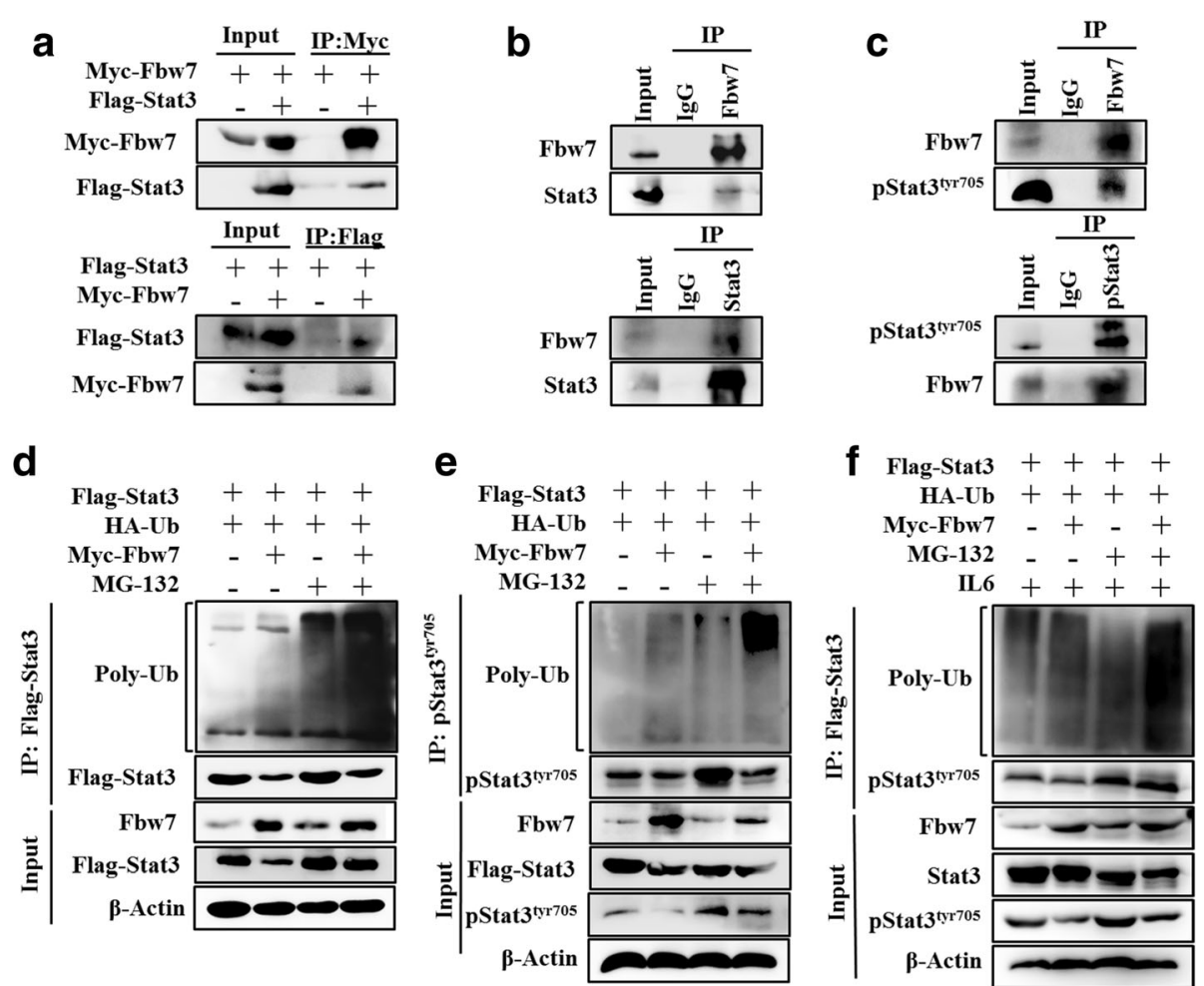

Fig. 4 Fbw7 interacts with and ubiquitinates Stat3. a Fbw7 interacts with Stat3 at exogenous levels. Immunoblotting analysis of lysates after immunoprecipitation from HEK293T cells transfected with Myc-Fbw7 and Flag-Stat3. b Fbw7 interacts with Stat3 at endogenous levels. Cell lysates from SU-DHL-2 cells were immunoprecipitated with anti-Fbw7 or anti-Stat3 antibody, followed by immunoblotting with anti-Fbw7 or anti-Stat3 antibody, respectively. IgG was used as a control. c Fbw7 interacts with pStat3 ${ }^{T y r 705}$ at endogenous levels. Cell lysates from SU-DHL-2 cells were immunoprecipitated with anti-Fbw7 or anti-pStat3 ${ }^{\text {Tyr705 }}$ antibody, followed by immunoblotting with anti-Fbw7 or anti- pStat3 ${ }^{\text {Tyr705 }}$ antibody, respectively. $\mathbf{d}$ and $\mathbf{e}$, Flag-Stat3 and HA-ubiquitin were co-expressed with Myc-Fbw7 in HEK293T cells. After cells were treated with or without 10 mM MG132 for 6 h, Stat3 and pStat3 ${ }^{\text {Tyr705 }}$ were immunoprecipitated with anti-Flag or anti-pStat3 ${ }^{\text {Tyr705 }}$ antibody, and the polyubiquitination status of Stat3 and pStat3 ${ }^{\text {Tyr705 }}$ was detected by immunoblotting. $\mathbf{f}$ similar to E, cells were treated with $10 \mathrm{ng} / \mathrm{L}$ IL6 for $6 \mathrm{~h}$ to activate Stat3 signaling. The experiments were repeated three times, and representative images of blots are shown

\section{Discussion}

The ubiquitin-ligase Fbw7 targets several protooncogenes for ubiquitination and degradation and acts as a tumor suppressor in many human malignancies. However, the Fbw7 substrates that have important roles in the development of specific cancers are unknown. Here, we investigated Fbw7 in ABC-DLBCL and found that Fbw7 targets Stat3 for ubiquitylation and degradation, and that Fbw7 inhibits downstream anti-apoptotic targets of Stat3.

DLBCL is attributable for nearly $40 \%$ of all nonHodgkin lymphoma diagnoses and has been divided into the molecular subtypes $\mathrm{GCB}$ and $\mathrm{ABC}$ by genetic profiling. Overall survival is significantly reduced in the $A B C$ DLBCL compared with the GCB-DLBCL. In our study, we found that Fbw7 expression was reduced in DLBCL associated with the ABC subtype (Fig. 1b). Low Fbw7 expression also correlated with a poor prognosis (Fig. 1d). We also demonstrate that Fbw7 is an apoptosis regulator through flow cytometry analysis and cell viability assays
(Fig. 2b and c). Previous studies have shown that Fbw7 targets c-Jun and Mcl-1, regulating apoptosis [18, 20], and these data interested us to investigate its molecular mechanism for regulating apoptosis in ABC-DLBCL.

Stat3, an important transcript factor in many human cancers, shows a high level of expression and activation in ABC-DLBCL [15]. Constitutive Stat3 activation is also a biomarker for poor prognosis after R-CHOP therapy [16]. Previous studies demonstrated Stat3 siRNA or kinase inhibitors reduced tumor proliferation in vitro [31]. These reports suggest targeting Stat 3 could be a promising approach to therapy in ABC-DLBCL. Our data confirmed Fbw7 targets Stat3 for ubiquitylation and degradation, especially Stat 3 phosphorylated at tyrosine 705. First, we found Fbw7 influenced the stability of Stat3 and pStat3 ${ }^{\text {Tyr705 }}$ in a dose-dependent manner (Fig. 3b). Further, we showed that Fbw7 interacts with Stat3 and pStat $3^{\text {Tyr705 }}$ in ABC-DLBCL cells by coimmunoprecipitation (Fig. 4a-c). Moreover, Fbw7 interacts with Stat3 and $\mathrm{pStat}^{\text {Tyr705 }}$ to regulate their 


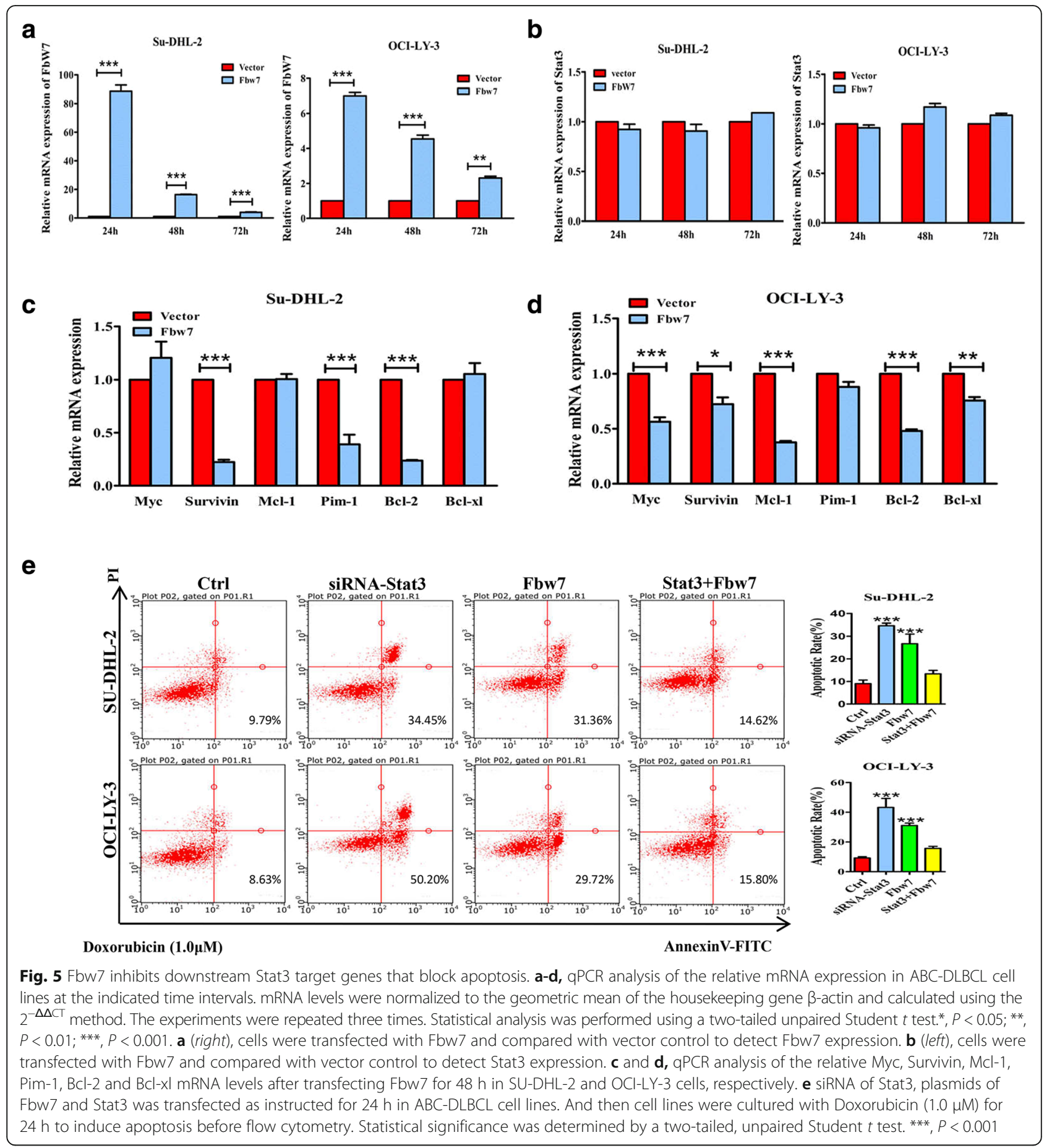

ubiquitylation and degradation. It has been reported that Fbw7 binds to its substrates after they have been phosphorylated within conserved phospho-degron motifs, called Cdc4 phospho-degrons (CPDs) [32]. Several studies have demonstrated that Fbw7 targets phosphorylated substrates, including Myc, c-Jun, Mcl-1, Notch and KLF2 [17, 18, 20-22]. The ability of Fbw7 to degrade these oncogenes, specifically, makes it a tumor suppressor. Our results showed that Fbw7 interacts with and degrades Stat3 in ABC-DLBCL, and therefore; may be a viable target for Stat3-directed therapy.

Stat3 is required for tumor cell proliferation, infiltration, differentiation and apoptosis inhibition. Stat3 is activated by phosphorylation, which produces a molecule that spontaneously dimerizes, binds to DNA and activates transcription of downstream target genes [10, 11], 


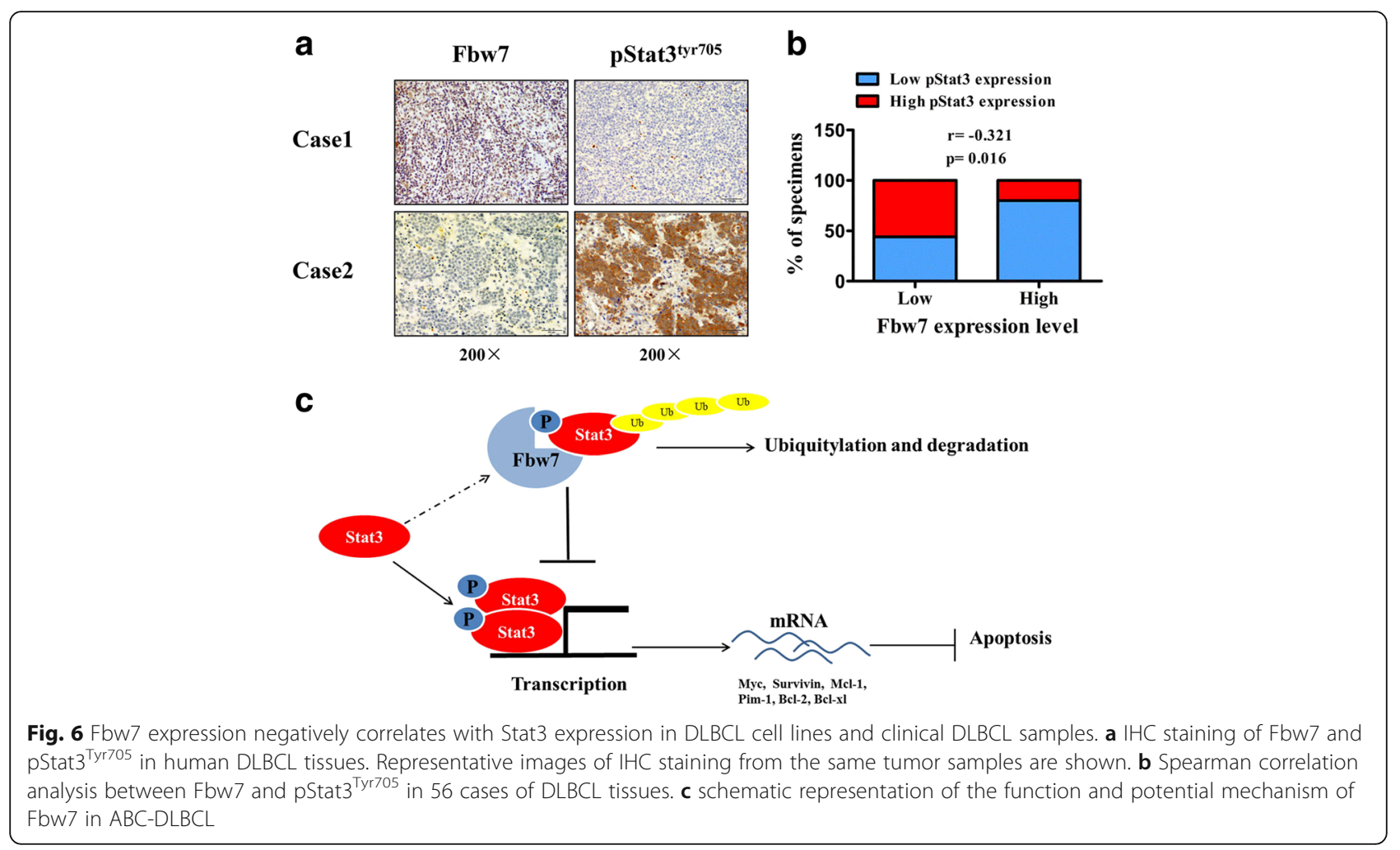

some of which block apoptosis, including Myc, Survivin, Bcl-2, Mcl-1, Pim-1 and Bcl-xl [33-36]. Our results also revealed that Fbw7 overexpression reduced mRNA levels of these target genes in a cell-dependent manner in ABC-DLBCL cell lines. There was a significant reduction in Survivin, Pim-1 and Bcl-2 mRNA levels in SU-DHL-2 cells (Fig. 5c, right), as well as a significant reduction in Myc, Survivin, Mcl-1, Bcl-2 and Bcl-xl mRNA levels in OCI-LY-3 cells (Fig. 5c, left). Thus, both our clinical and experimental data suggest Fbw7 regulates Stat3 stability and downstream signaling, making it a promising target for therapy. Although it is well known that cyclin D1 is the target gene of Stat 3 which regulates cell proliferation and cell cycle, qPCR revealed that Fbw7 overexpression did not result in significant reduction of cyclin D1 (Additional file 6). And the results of CCK8 proliferation assays and cell cycle did not show significant difference after Fbw7 overexpression in ABC-DLBCL cell lines (Additional file 4). It's reported that only $2.1 \%$ of patients in total of 1435 express cyclin D1 in DLBCL [37]. Therefore our negative results of cyclin D1 may be related to its missing expression. Moreover, Fbw7induced degradation of STAT3 is more important than other reported tumorigenesis including Myc, Notch, Jun, DEK and MCL1 in ABC-DLBCL (Additional file 7).

Fbw7 regulates a proliferative network that includes several oncogenes, and therefore, is considered a tumor suppressor in human cancers. There may be a viable approach for therapies directed at Fbw7 and its substrates. Studies have shown that Fbw7 expression is regulated by upstream proteins including p53, EBP2, Numb4, Pin1 and Hes-5 [38-41]. In addition, multiple microRNAs, including miR-25, miR-129-5p and miR223 have also been demonstrated to regulate Fbw7 expression [42-44]. Together, these factors comprise a complex regulatory network that controls Fbw7 expression. However, exploiting this regulatory network for a means to restore or increase Fbw7 expression requires a deeper understanding of its transcriptional and posttranscriptional regulation. Further research into the upstream pathways that phosphorylate Stat3, marking it for Fbw7-mediated ubiquitylation, could also be a promising approach for drug discovery in ABC-DLBCL.

\section{Conclusions}

In this study, we investigated the role of Fbw7 in $\mathrm{ABC}$ $D L B C L$, and found it showed reduced expression in non-GCB DLBCL, which was associated with a poor outcome. Fbw7 expression promotes apoptosis in ABCDLBCL cell lines. Furthermore, we demonstrated that Fbw7 targets Stat3 and especially activated Stat3 for ubiquitylation to regulate its stability. QPCR analysis also demonstrated that the downstream target genes of Stat3 which mediate anti-apoptotic effects were downregulated following Fbw7 expression in ABC-DLBCL. Together, our data clearly show that the ubiquitin-ligase 
Fbw7 targets Stat3 for ubiquitylation and degradation to regulate apoptosis in ABC-DLBCL, and our study may offer a promising approach for therapy by offering a new method of Stat3 inhibition.

\section{Additional files}

Additional file 1: Correlation between Fbw7 expression and clinicpathological variables in 165 DLBCL cases. (DOCX $16 \mathrm{~kb}$ )

Additional file 2: Data of clinicpathological variables in $165 \mathrm{DLBCL}$ cases. (XLS $314 \mathrm{~kb}$ )

Additional file 3: Primers for quantitative PCR. (DOCX $16 \mathrm{~kb}$ )

Additional file 4: Overexpression of Fbw7 did not inhibit proliferation in ABC-DLBCL cells. A, cell proliferation viability analysed by CCK8 assays. B, Flow-cytometry analyses of the cell cycle of the indicated ABC-DLBCL cells after transfecting Fbw7 for $48 \mathrm{~h}$. Statistical analysis was performed using a two-tailed unpaired Student $t$ test. (TIF $676 \mathrm{~kb}$ )

Additional file 5: Fbw7 interacts with Stat3 and pStat $3^{\text {tyr705 }}$ in HEK293T cells. A and B, Interaction between endogenous Fbw7 and Stat3 in HEK293T cells. Cell lysates were immunoprecipitated with anti-Fbw7, anti-Stat3 or anti-pStat3 $3^{\text {Tyr705 }}$ antibody followed by immunoblotting with anti-Fbw7, anti-Stat3 or anti-pStat3 ${ }^{\text {Tyr705}}$, respectively. IgG was used as a control. (TIF $432 \mathrm{~kb}$ )

Additional file 6: Relative mRNA expression of cyclin D1. QPCR revealed that Fbw7 overexpression did not result in significant reduction of cyclin D1. (TIF $40 \mathrm{~kb}$ )

Additional file 7: Fbw7-induced degradation of STAT3 is more important than other reported tumorigenesis in ABC-DLBCL. A, western blotting showed overexpression of Fbw7 inhibit Stat3 more significant than other reported substrates of Fbw7 including Myc, Notch, Jun, DEK and MCL1. And the results of relative intensity were shown. B, Fbw7 decreases the stability of Stat3 more significant than other reported substrates of Fbw7 including Myc, Notch, Jun, DEK and MCL1. (TIF 680 kb)

\section{Abbreviations}

ABC: Activated B-cell; DLBCL: Diffuse large B-cell lymphoma; FBS: Fetal bovine serum; GCB: Germinal center B-cell; HSC: Hematopoietic stem cell; IHC: Immunohistochemistry; NF-kB: Nuclear factor-kb; R-CHOP: Rituximab plus cyclophosphamide, doxorubicin, vincristine, and prednisone;

Stat3: Signal transducer and activator of transcription 3

\section{Acknowledgements}

Not applicable.

\section{Funding}

This work was supported by the National Natural Science Foundation of China (81172244).

\section{Availability of data and materials}

The data supporting our findings were shown in supplementary files.

\section{Authors' contributions}

Conception and design: Y-HL, F-PX. Acquisition of data (acquired and managed patients, provided facilities etc.): SY, F-PX, YC, H-JH, LL, X-LL, JX, D-LL, X-LZ. Analysis and interpretation of data (statistical analysis, biostatistics, computational analysis): SY, YC, D-YL, FZ. Writing of the manuscript: Y-HL, SY. Study supervision: Y-HL. All authors read and approved the final manuscript.

\section{Competing interests}

The authors declare that they have no competing interests.

\section{Consent for publication}

Not applicable.

\section{Ethics approval and consent to participate}

This study was approved by the Research Ethics Committee of Guangdong General Hospital, Guangdong Academy of Medical Science, and written informed consent was obtained from all patients. The number of the Research Ethics Committee's approval letter is GDREC2016288H.

\section{Author details}

'Department of Pathology, Guangdong General Hospital \& Guangdong Academy of Medical Sciences, Guangzhou, Guangdong 510080, People's Republic of China. ${ }^{2}$ Department of Pathology, Dongguan People's Hospital, Dongguan, Guangdong 523059, People's Republic of China.

Received: 20 August 2016 Accepted: 14 December 2016 Published online: 10 January 2017

\section{References}

1. Coiffier B. Immunochemotherapy: The new standard in aggressive nonHodgkin's lymphoma in the elderly. Semin Oncol. 2003;30(1):21-7.

2. Alizadeh AA, Eisen MB, Davis RE, Ma C, Lossos IS, Rosenwald A, Boldrick JC, Sabet H, Tran T, Yu X, Powell JI, Yang L, Marti GE, Moore T, Hudson Jr J, Lu L, Lewis DB, Tibshirani R, Sherlock G, Chan WC, Greiner TC, Weisenburger DD, Armitage JO, Warnke R, Levy R, Wilson W, Grever MR, Byrd JC, Botstein D, Brown PO, Staudt LM. Distinct types of diffuse large B-cell lymphoma identified by gene expression profiling. Nature. 2000;403(6769):503-11.

3. Lenz G, Wright GW, Emre NC, Kohlhammer H, Dave SS, Davis RE, Carty S, Lam LT, Shaffer AL, Xiao W, Powell J, Rosenwald A, Ott G, Muller-Hermelink HK, Gascoyne RD, Connors JM, Campo E, Jaffe ES, Delabie J, Smeland EB, Rimsza LM, Fisher RI, Weisenburger DD, Chan WC, Staudt LM. Molecular subtypes of diffuse large B-cell lymphoma arise by distinct genetic pathways. Proc Natl Acad Sci U S A. 2008;105(36):13520-5.

4. Wright G, Tan B, Rosenwald A, Hurt EH, Wiestner A, Staudt LM. A gene expression-based method to diagnose clinically distinct subgroups of diffuse large B cell lymphoma. Proc Natl Acad Sci U S A. 2003;100(17):9991-6.

5. Hans CP, Weisenburger DD, Greiner TC, Gascoyne RD, Delabie J, Ott G, Müller-Hermelink HK, Campo E, Braziel RM, Jaffe ES, Pan Z, Farinha P, Smith LM, Falini B, Banham AH, Rosenwald A, Staudt LM, Connors JM, Armitage JO, Chan WC. Confirmation of the molecular classification of diffuse large B-cell lymphoma by immunohistochemistry using a tissue microarray. Blood. 2004;103(1):275-82.

6. Dunleavy K, Pittaluga S, Czuczman MS, Dave SS, Wright G, Grant N, Shovlin M, Jaffe ES, Janik JE, Staudt LM, Wilson WH. Differential efficacy of bortezomib plus chemotherapy within molecular subtypes of diffuse large B-cell lymphoma. Blood. 2009;113(24):6069-76.

7. Ceribelli M, Kelly PN, Shaffer AL, Wright GW, Xiao W, Yang Y, Mathews Griner LA, Guha R, Shinn P, Keller JM, Liu D, Patel PR, Ferrer M, Joshi S, Nerle S, Sandy P, Normant E, Thomas CJ, Staudt LM. Blockade of oncogenic IkappaB kinase activity in diffuse large B-cell lymphoma by bromodomain and extraterminal domain protein inhibitors. Proc Natl Acad Sci U S A. 2014;111(31):11365-70.

8. Scuto A, Kujawski M, Kowolik C, Krymskaya L, Wang L, Weiss LM, Digiusto D, Yu H, Forman S, Jove R. STAT3 Inhibition Is a Therapeutic Strategy for ABClike Diffuse Large B-Cell Lymphoma. Cancer Res. 2011;71(9):3182-8.

9. Lam LT, Wright G, Davis RE, Lenz G, Farinha P, Dang L, Chan JW, Rosenwald A, Gascoyne RD, Staudt LM. Cooperative signaling through the signal transducer and activator of transcription 3 and nuclear factor-\{kappa\}B pathways in subtypes of diffuse large B-cell lymphoma. Blood. 2008;111(7):3701-13.

10. Hirano T, Ishihara K, Hibi M. Roles of STAT3 in mediating the cell growth, differentiation and survival signals relayed through the IL- 6 family of cytokine receptors. Oncogene. 2000;19(21):2548-56.

11. Yu H, Jove R. The STATs of cancer-new molecular targets come of age. Nat Rev Cancer. 2004;4(2):97-105.

12. Kasprzycka M, Marzec M, Liu X, Zhang Q, Wasik MA. Nucleophosmin/anaplastic lymphoma kinase (NPM/ALK) oncoprotein induces the T regulatory cell phenotype by activating STAT3. Proc Natl Acad Sci U S A. 2006;103(26):9964-9.

13. Schaper F, Gendo C, Eck M, Schmitz J, Grimm C, Anhuf D, Kerr IM, Heinrich PC. Activation of the protein tyrosine phosphatase SHP2 via the interleukin6 signal transducing receptor protein gp130 requires tyrosine kinase Jak1 and limits acute-phase protein expression. Biochem J. 1998;335(Pt 3):557-65.

14. Narimatsu M, Maeda H, Itoh S, Atsumi T, Ohtani T, Nishida K, Itoh M, Kamimura D, Park SJ, Mizuno K, Miyazaki J, Hibi M, Ishihara K, Nakajima $K$, Hirano T. Tissue-specific autoregulation of the stat3 gene and its 
role in interleukin-6-induced survival signals in T cells. Mol Cell Biol. 2001;21(19):6615-25.

15. Ding BB, Yu JJ, Yu RY, Mendez LM, Shaknovich R, Zhang Y, Cattoretti G, Ye BH. Constitutively activated STAT3 promotes cell proliferation and survival in the activated B-cell subtype of diffuse large B-cell lymphomas. Blood. 2008;111(3):1515-23.

16. Huang X, Meng B, lqbal J, Ding BB, Perry AM, Cao W, Smith LM, Bi C, Jiang C, Greiner TC, Weisenburger DD, Rimsza L, Rosenwald A, Ott G, Delabie J, Campo E, Braziel RM, Gascoyne RD, Cook JR, Tubbs RR, Jaffe ES, Armitage JO, Vose JM, Staudt LM, McKeithan TW, Chan WC, Ye BH, Fu K. Activation of the STAT3 Signaling Pathway Is Associated With Poor Survival in Diffuse Large B-Cell Lymphoma Treated With R-CHOP. J Clin Oncol Off J Am Soc Clin Oncol. 2011:31(36):4520-8.

17. Yada M, Hatakeyama S, Kamura T, Nishiyama M, Tsunematsu R, Imaki H, Ishida N, Okumura F, Nakayama K, Nakayama Kl. Phosphorylation-dependent degradation of c-Myc is mediated by the F-box protein Fbw7. EMBO J. 2004;23(10):2116-25.

18. Nateri AS, Riera-Sans L, Da Costa C, Behrens A. The Ubiquitin Ligase SCFFbw7 Antagonizes Apoptotic JNK Signaling. Science. 2004;303(5662):1374-8.

19. Tsunematsu R, Nakayama K, Oike Y, Nishiyama M, Ishida N, Hatakeyama S, Bessho Y, Kageyama R, Suda T, Nakayama Kl. Mouse Fbw7/Sel-10/Cdc4 Is Required for Notch Degradation during Vascular Development. J Biol Chem. 2004;279(10):9417-23.

20. Inuzuka H, Shaik S, Onoyama I, Gao D, Tseng A, Maser RS, Zhai B, Wan L, Gutierrez A, Lau AW, Xiao Y, Christie AL, Aster J, Settleman J, Gygi SP, Kung AL, Look T, Nakayama KI, DePinho RA, Wei W. SCF FBW7 regulates cellular apoptosis by targeting MCL1 for ubiquitylation and destruction. Nature. 2011;471(7336):104-9.

21. Babaei-Jadidi R, Li N, Saadeddin A, Spencer-Dene B, Jandke A, Muhammad B, Ibrahim EE, Muraleedharan R, Abuzinadah M, Davis H, Lewis A, Watson S, Behrens A, Tomlinson I, Nateri AS. FBXW7 influences murine intestinal homeostasis and cancer, targeting Notch, Jun, and DEK for degradation. J Exp Med. 2011;208(2):295-312.

22. Wang R, Wang Y, Liu N, Ren C, Jiang C, Zhang K, Yu S, Chen Y, Tang H, Deng Q, Fu C, Wang Y, Li R, Liu M, Pan W, Wang P. FBW7 regulates endothelial functions by targeting KLF2 for ubiquitination and degradation. Cell Res. 2013;23(6):803-19.

23. Wei W, Jin J, Schlisio S, Harper JW, Kaelin Jr WG. The v-Jun point mutation allows c-Jun to escape GSK3-dependent recognition and destruction by the Fbw7 ubiquitin ligase. Cancer Cell. 2005;8(1):25-33.

24. Sancho R, Jandke A, Davis H, Diefenbacher ME, Tomlinson I, Behrens A. Fbox and WD Repeat Domain-Containing 7 Regulates Intestinal Cell Lineage Commitment and Is a Haploinsufficient Tumor Suppressor. Gastroenterology. 2010;139(3):929-41.

25. Arabi A, Ullah K, Branca RM, Johansson J, Bandarra D, Haneklaus M, Fu J, Ariës I, Nilsson P, Den Boer ML, Pokrovskaja K, Grandér D, Xiao G, Rocha S, Lehtiö J, Sangfelt O. Proteomic screen reveals Fbw7 as a modulator of the NF-KB pathway. Nat Commun. 2012;3:976.

26. Akhoondi S, Sun D, von der Lehr N, Apostolidou S, Klotz K, Maljukova A, Cepeda D, Fiegl H, Dafou D, Marth C, Mueller-Holzner E, Corcoran M, Dagnell M, Nejad SZ, Nayer BN, Zali MR, Hansson J, Egyhazi S, Petersson F, Sangfelt P, Nordgren H, Grander D, Reed SI, Widschwendter M, Sangfelt O, Spruck C. FBXW7/hCDC4 Is a General Tumor Suppressor in Human Cancer. Cancer Res. 2007;67(19):9006-12.

27. Tetzlaff MT, Yu W, Li M, Zhang P, Finegold M, Mahon K, Harper JW, Schwartz RJ, Elledge SJ. Defective cardiovascular development and elevated cyclin E and Notch proteins in mice lacking the Fbw7 F-box protein Proc Natl Acad Sci U S A. 2004;101(10):3338-45.

28. Perry JM, Li L. Self-renewal versus transformation: Fbxw7 deletion leads to stem cell activation and leukemogenesis. Genes Dev. 2008;22(9):1107-9.

29. Thompson BJ, Jankovic V, Gao J, Buonamici S, Vest A, Lee JM, Zavadil J, Nimer SD, Aifantis I. Control of hematopoietic stem cell quiescence by the E3 ubiquitin ligase Fbw7. J Exp Med. 2008;205(6):1395-408.

30. Reavie L, Della Gatta G, Crusio K, Aranda-Orgilles B, Buckley SM, Thompson B, Lee E, Gao J, Bredemeyer AL, Helmink BA, Zavadil J, Sleckman BP, Palomero T, Ferrando A, Aifantis I. Regulation of hematopoietic stem cell differentiation by a single ubiquitin ligase-substrate complex. Nat Immunol. 2010;11(3):207-15.

31. Yang C, Lu P, Lee FY, Chadburn A, Barrientos JC, Leonard JP, Ye F, Zhang D, Knowles DM, Wang YL. Tyrosine kinase inhibition in diffuse large B-cell lymphoma: molecular basis for antitumor activity and drug resistance of dasatinib. Leukemia. 2008;22(9):1755-66.
32. Hao B, OehImann S, Sowa ME, Harper JW, Pavletich NP. Structure of a Fbw7Skp1-cyclin E complex: multisite-phosphorylated substrate recognition by SCF ubiquitin ligases. Mol Cell. 2007;26(1):131-43.

33. Gupta M, Han JJ, Stenson M, Wellik L, Witzig TE. Regulation of STAT3 by histone deacetylase-3 in diffuse large B-cell lymphoma: implications for therapy. Leukemia. 2012;26(6):1356-64.

34. Zhang X, Yue P, Page BD, Li T, Zhao W, Namanja AT, Paladino D, Zhao J, Chen Y, Gunning PT, Turkson J. Orally bioavailable small-molecule inhibitor of transcription factor Stat3 regresses human breast and lung cancer xenografts. Proc Natl Acad Sci U S A. 2012;109(24):9623-8.

35. Nam S, Buettner R, Turkson J, Kim D, Cheng JQ, Muehlbeyer S, Hippe F, Vatter S, Merz KH, Eisenbrand G, Jove R. Indirubin derivatives inhibit Stat3 signaling and induce apoptosis in human cancer cells. Proc Natl Acad Sci U S A. 2005;102(17):5998-6003.

36. Shirogane T, Fukada T, Muller JM, Shima DT, Hibi M, Hirano T. Synergistic Roles for Pim-1 and c-Myc in STAT3-Mediated Cell Cycle Progression and Antiapoptosis. Immunity. 1999;11(6):709-19.

37. OK CY, Xu-Monette ZY, Tzankov A, O'Malley DP, Montes-Moreno S, Visco C, Møller MB, Dybkaer K, Orazi A, Zu Y, Bhagat G, Richards KL, Hsi ED, Han van Krieken J, Ponzoni M, Farnen JP, Piris MA, Winter JN, Medeiros $L$, Young KH. Prevalence and clinical implications of cyclin D1 expression in diffuse large B-cell lymphoma (DLBCL) treated with immunochemotherapy: a report from the International DLBCL Rituximab-CHOP Consortium Program. Cancer. 2014;120(12):1818-29.

38. Kimura T, Gotoh M, Nakamura Y, Arakawa H. hCDC4b, a regulator of cyclin E, as a direct transcriptional target of p53. Cancer Sci. 2003;94(5):431-6.

39. Welcker M, Larimore EA, Frappier L, Clurman BE. Nucleolar Targeting of the Fbw7 Ubiquitin Ligase by a Pseudosubstrate and Glycogen Synthase Kinase 3. Mol Cell Biol. 2011;31(6):1214-24.

40. Jiang $X$, Xing H, Kim TM, Jung Y, Huang W, Yang HW, Song S, Park PJ, Carroll RS, Johnson MD. Numb Regulates Glioma Stem Cell Fate and Growth by Altering Epidermal Growth Factor Receptor and Skp1-Cullin-FBox Ubiquitin Ligase Activity. STEM CELLS. 2012;30(7):1313-26.

41. Farrell AS, Pelz C, Wang X, Daniel CJ, Wang Z, Su Y, Janghorban M, Zhang $X$ Morgan C, Impey S, Sears RC. Pin1 Regulates the Dynamics of c-Myc DNA Binding To Facilitate Target Gene Regulation and Oncogenesis. Mol Cell Biol. 2013;33(15):2930-49.

42. Lu D, Davis MP, Abreu-Goodger C, Wang W, Campos LS, Siede J, Vigorito E, Skarnes WC, Dunham I, Enright AJ, Liu P. MiR-25 regulates Wwp2 and Fbxw7 and promotes reprogramming of mouse fibroblast cells to iPSCs. PLoS One. 2012;7(8):e40938.

43. Häsler R, Jacobs G, Till A, Grabe N, Cordes C, Nikolaus S, Lao K, Schreiber S, Rosenstiel P. Microbial pattern recognition causes distinct functional microRNA signatures in primary human monocytes. PLoS One. 2012;7(2):e31151.

44. Li J, Guo Y, Liang X, Sun M, Wang G, De W, Wu W. MicroRNA-223 functions as an oncogene in human gastric cancer by targeting FBXW7/hCdc4. J Cancer Res Clin Oncol. 2012;138(5):763-74.

\section{Submit your next manuscript to BioMed Central and we will help you at every step:}

- We accept pre-submission inquiries

- Our selector tool helps you to find the most relevant journal

- We provide round the clock customer support

- Convenient online submission

- Thorough peer review

- Inclusion in PubMed and all major indexing services

- Maximum visibility for your research

Submit your manuscript at www.biomedcentral.com/submit
Biomed Central 